5. Lu J, Gu J, Li K, et al. COVID-19 outbreak associated with air conditioning in restaurant, Guangzhou, China, 2020. Emerg Infect Dis 2020;26:1628-1631.

6. Doremalen, N, Bushmaker, T, Morris D, et al. Aerosol and surface stability of SARS-CoV-2 as compared with SARS-CoV-1. N Engl J Med 2020;382:1564-1567.

7. Otter JA, Donskey C, Yezli S, Douthwaite S, Goldenberg SD, Weber DJ. Transmission of SARS and MERS coronaviruses and influenza virus in healthcare settings: possible role of dry surface contamination. $J$ Hosp Infect 2016;92:235-250.
8. Boone SA, Gerba CP. Significance of fomites in the spread of respiratory and enteric viral disease. Appl Environ Microbiol 2007;73:1687-1696.

9. Tomas ME, Kundrapu S, Thota $\mathrm{P}$, et al. Contamination of health care personnel during removal of personal protective equipment. JAMA Intern Med 2015;175:1904-1910.

10. Hirose R, Ikegaya H, Naito $\mathrm{Y}$, et al. Survival of SARS-CoV-2 and influenza virus on the human skin: importance of hand hygiene in COVID-19. Clin Infect Dis 2020. doi: 10.1093/cid/ciaa1517.

\title{
Delayed recognition of community transmission of COVID-19 resulting in healthcare worker infections
}

\author{
Raymund B. Dantes MD, MPH (1), Tait T. Jones MD and David C. Neujahr MD \\ Emory University School of Medicine, Atlanta, Georgia
}

Letter to the Editor-We describe a case of delayed COVID-19 diagnosis due to unrecognized community transmission in Atlanta, Georgia, in mid-February 2020. This case resulted in transmission of COVID-19 to 3 of the 4 healthcare workers present during a diagnostic bronchoscopy procedure where only procedural masks were worn.

On February 28, 2020 the Centers for Disease Control and Prevention (CDC) announced guidelines recommending COVID19 testing for persons with compatible symptoms and either recent travel to COVID-19 affected regions, contact with known COVID19 cases, or "fever with severe acute lower respiratory illness (eg, pneumonia, acute respiratory distress syndrome [ARDS] requiring hospitalization and without an alternative explanatory diagnosis)" (Fig 1). ${ }^{1}$

On March 2, 2020, Georgia officials announced the first 2 cases of coronavirus disease 2019 (COVID-19) in the state, among a Fulton County man who had recently returned from Italy, and his teenaged son. ${ }^{2}$ On the same date, a man aged in his 40 s without any known comorbidities presented to the emergency department (ED) for the evaluation of persistent fevers, which began around February 21, 2020. His only other symptom was very mild dyspnea on exertion. He denied any travel outside of the Atlanta area over the past several years. A family member at home had a febrile illness and was recovering at home. He also had a coworker with a febrile illness, but neither contact had any recent travel history. The patient worked in a nearby restaurant frequented by CDC and Emory University employees during lunch breaks, and he resided in Atlanta, Georgia.

His initial evaluation in the ED showed normal vital signs and flu and respiratory syncytial virus rapid tests were negative. He was admitted to the medical floor for further evaluation, where droplet and contact precautions were continued for the remainder of hospitalization. Subsequent evaluation revealed a negative HIV test and negative respiratory viral panel. A computerized tomography scan of the chest revealed "peripheral ground-glass with associated

Author for correspondence: Raymund Dantes, E-mail: Raymund.dantes@ emoryhealthcare.org

Cite this article: Dantes RB, Jones TT, and Neujahr DC. (2021). Delayed recognition of community transmission of COVID-19 resulting in healthcare worker infections. Infection Control \& Hospital Epidemiology, 42: 1528-1529, https://doi.org/10.1017/ice.2020.285 consolidation worse in bilateral lower lobes." Severe acute respiratory coronavirus virus 2 (SARS-CoV-2) testing was considered and discussed among the hospital medicine, infectious disease, and pulmonary consultation services; however, the patient did not meet the recommended CDC criteria for novel coronavirus testing at that time because he had no relevant travel history, contact with known cases, or severe illness. No commercial or other testing options were available at the time.

On the third day of his hospitalization, he underwent diagnostic bronchoscopy, and staff wore procedural masks. The patient was discharged later that day because he was feeling well and his fever had resolved. He was instructed to remain isolated at home for at least 1 week. Bronchoalveolar lavage fluid was sent for bacterial, fungal, and AFB cultures, which were negative. BAL fluid cellular differential was notable for having $94 \%$ macrophages. Cytology was negative for microorganisms, and a Biofire FilmArray Respiratory panel was negative. On March 11, as more SARSCoV-2 testing capacity became available, his remaining bronchial fluid was mailed to Associated Regional and University Pathologists (ARUP), and it tested positive for SARS-CoV2 virus on reverse transcriptase PCR testing on March 14.

The patient was notified of his test results by telephone, and he reported feeling well with no reoccurrence of fevers or other new symptoms. Within the following week, 3 of the 4 healthcare workers present during the bronchoscopy tested positive for SARS-CoV-2.

This case provides evidence of community transmission of SARS-CoV-2 in Atlanta, Georgia, likely between February 10 and February 19, 2020, based on our current knowledge of the incubation period for SARS-CoV-2. ${ }^{3}$ The precise source of this patient's COVID-19 remains unknown, but it may have been acquired from either his coworker or a family contact. Due to both restrictive CDC testing criteria and a lack of available SARS-CoV-2 testing outside of public health laboratories, this patient was not diagnosed when rapid public health actions, including contact tracing and isolation, could have limited community spread of this disease. This case also illustrates the risk of SARS-CoV-2 transmission to healthcare workers during bronchoscopy when COVID-19 is not recognized and procedural masks are used instead of N95 or other high-level respirators.

(c) The Author(s), 2020. Published by Cambridge University Press on behalf of The Society for Healthcare Epidemiology of America. This is an Open Access article, distributed under the terms of the Creative Commons Attribution licence (http://creativecommons.org/licenses/by/4.0/), which permits unrestricted re-use, distribution, and reproduction in any medium, provided the original work is properly cited. 


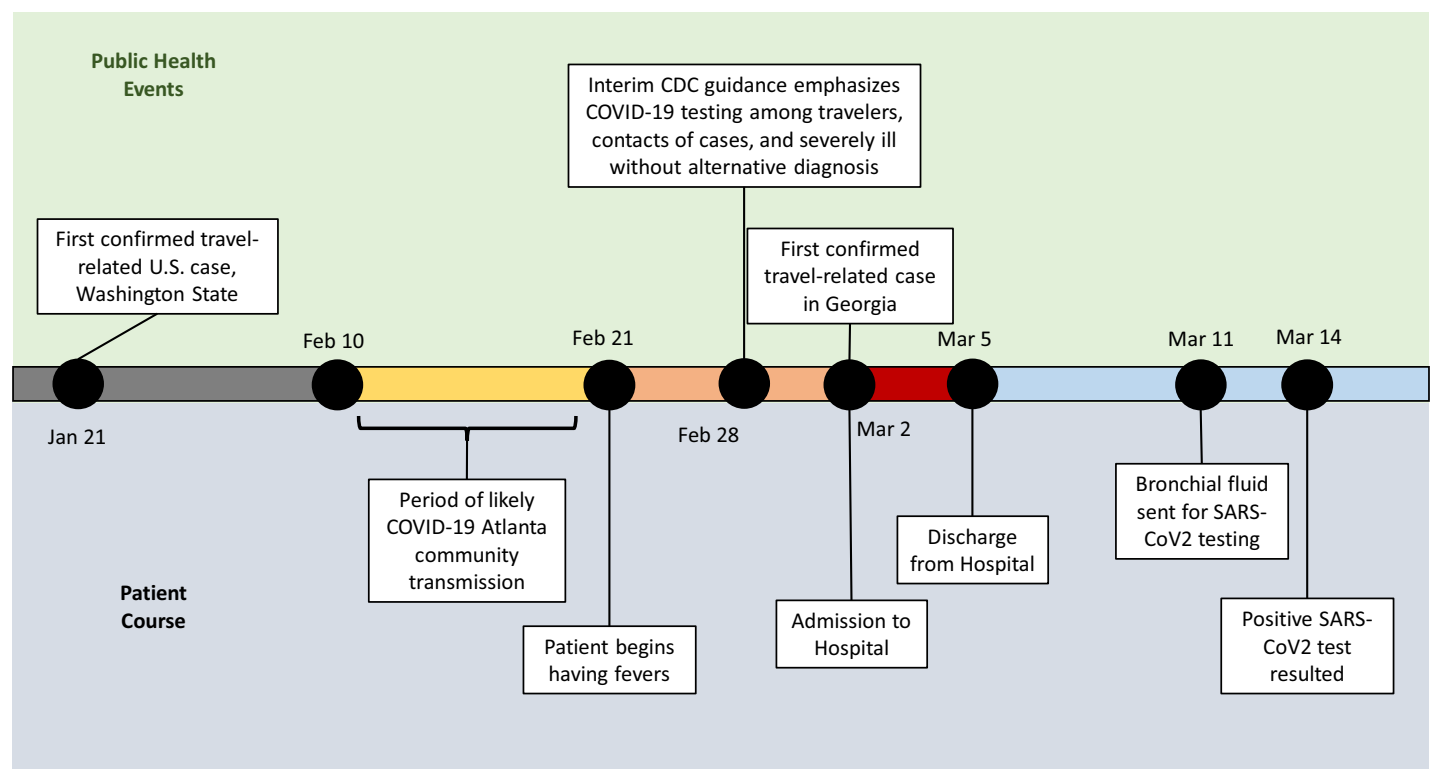

Fig. 1. Timeline of public health events and patient course, January 21 through March 14, 2020.

\section{Acknowledgments.}

Financial support. No financial support was provided relevant to this article.

Conflicts of interest. All authors report no conflicts of interest relevant to this article.

\section{References}

1. Update and interim guidance on outbreak of coronavirus disease 2019 (COVID-19). Centers for Disease Control and Prevention website. https://
emergency.cdc.gov/han/2020/HAN00428.asp. Published February 28, 2020, Accessed April 4, 2020.

2. Gov. Kemp, officials confirm two cases of COVID-19 in Georgia. Georgia Department of Public Health website. https://dph.georgia.gov/press-releases/ 2020-03-02/gov-kemp-officials-confirm-two-cases-covid-19-georgia. Published March 2, 2020. Accessed April 4, 2020.

3. Lauer SA, Grantz KH, Bi Q, et al. The incubation period of coronavirus disease 2019 (COVID-19) from publicly reported confirmed cases: estimation and application. Ann Intern Med 2020 March 10 [Epub ahead of print]. doi: https://doi.org/10.7326/M20-0504.

\title{
Pooling is an insufficient strategy to avoid healthcare staff to patient transmission of severe acute respiratory coronavirus virus 2 (SARS-CoV-2)
}

\author{
Jessica Lüsebrink PhD, Verena Schildgen PhD and Oliver Schildgen PhD (1) \\ Kliniken der Stadt Köln, Klinikum der Privaten Universität Witten/Herdecke, Institut für Pathologie, Köln (Cologne), Germany
}

To the Editor-Since the start of the coronavirus disease 2019 (COVID-19) pandemic, the need for diagnostic testing to detect infections and to interrupt infection chains has become more and more important. Especially in the healthcare sector, testing of employees is important to maintain basic medical care and to avoid transmissions of severe acute respiratory coronavirus virus

Author for correspondence: Prof. Dr. rer. nat. Oliver Schildgen, E-mail: schildgeno@ kliniken-koeln.de or oliver.schildgen@uni-wh.de

Cite this article: Lüsebrink J, Schildgen V, and Schildgen O. (2021). Pooling is an insufficient strategy to avoid healthcare staff to patient transmission of severe acute respiratory coronavirus virus 2 (SARS-CoV-2). Infection Control \& Hospital Epidemiology, 42: 1529-1532, https://doi.org/10.1017/ice.2020.1340
2 (SARS-CoV-2) from medical staff to patients, of whom many have an increased risk for serious clinical COVID-19 courses.

Our laboratory has been testing the staff of our hospital since the beginning of the pandemic. Like most laboratories, we have suffered from supply bottlenecks, especially with extraction kits. Therefore, we implemented pooling strategies that to respond to increasing test requests; such approaches have been discussed by other colleagues. ${ }^{1}$

Most of the specimens analyzed for our hospital staff screening have been throat washes from gargling with $\mathrm{NaCl}$ solution, as previously described. ${ }^{2}$ We reintroduced this well-known method $^{3}$ due to the first shortage of swabs in the early phase of the pandemic in March 2020. A minority of orders received by our laboratory are

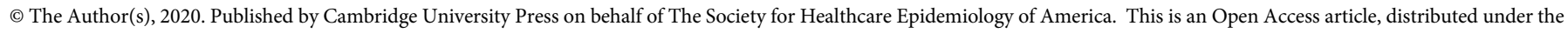

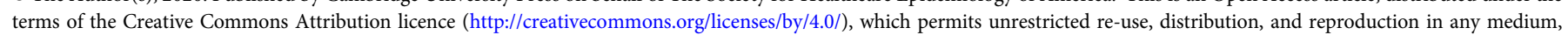
provided the original work is properly cited. 